\title{
Physicochemical and Fire Resistance Characteristics of Artificial Pozzolanic Cement Pastes
}

\author{
H. El-Didamony and Kh. A. Khalil* \\ Faculty of Science, Zagazig University,Zagzig, Egypt.
}

\begin{abstract}
7 HE PRESENT work describes details concerning preparation and physico-chemical characterization of pozzolanic cement pastes . The prepared cement pastes were examined by using XRD, SEM and nitrogen adsorption at $-196^{\circ} \mathrm{C}$. The results revealed that the physicochemical and mechanical properties of the solids investigated could be related to the microstructure and surface properties of the hardened pozzolanic cement pastes. It was found that the pozzolanic cement blend containing $20 \%$ Homera has the highest to fire resistance.
\end{abstract}

Keywords: Ground clay brick, Surface, Compressive strength and Fire resistance.

Fire is one of the hazards that attacks the building. The damage occurring takes place due exposure to fire. Chemical processes stimulated with temperature on cement phases have a significant influence on the thermal deformation, cracking, spelling and compressive strength losses. In these processes, the loss of physisorbed and chemically combined water much affect the capillary and gel porosity as well as the microstructure due to collapse CSH gel (calcium silicate hydrate) ${ }^{(1)}$. The amount of adsorbed and chemically combined water may take place at temperatures ranged between 100 and $300^{\circ} \mathrm{C}$. The increase in calcinations temperature within $300-550^{\circ} \mathrm{C}$ decreased effectively the mechanical of the calcined solids. This decrease varies between 15 and $70 \%$.

Homra is a waste product of about $5-10 \%$ produced from the manufacture of clay bricks in Egypt. It shows slow rate and heat of hydration. The utilization of this by-product is widely used to reduce cost, energy and pollution. Homra acts as a good pozzolanic material and filler in filled pozzolanic cement ${ }^{(2-4)}$. Homra is a pozzolanic material which is used to increase strength and reduce the permeability.

The pozzolanic material depletes $\mathrm{Ca}(\mathrm{OH})_{2}$ liberated from the hydration of OPC ( Ordinary Portland Cement ) to produce additional CSH(calcium silicate hydrate) as well as CASH(calcium alumino silicate hydrate) therefore, it enhances the fire resistance. Furthermore, pozzolanic materials are expected to play a significant role in the self -heating process of high strength concrete, when damaged through transformation of $\mathrm{Ca}(\mathrm{OH})_{2}$ into $\mathrm{CSH}$ deposited in pores and cracks in samples. It has been reported ${ }^{(5)}$ that when crushed brick used as a partial cement replacement of mortar or concrete, this improves the properties

*Corresponding author. Tel.: 0020552363728, mobile : 00201110808356, Fax: 0020552308213 
including reduction in permeability and resistance to sulfate attack as well as alkali-aggregate reaction. The partially replacing of cement by finely ground finally bricks gives early strength lower than that of the control. At 90 days, however, the strengths are the same or greater than those of the control ${ }^{(6)}$. It was also found that ${ }^{(7)}$ partially substituted cement by Homra shows that 20 wt \% Homra improves the compressive strength by about $25 \%$ but at 10 and $30 \mathrm{wt} \%$, the strength increases by $4.0 \%$ and $8.5 \%$ at $600^{\circ} \mathrm{C}$. This result is also due to the pozzolanic reaction of Homra with liberated lime to produce additional amounts of calcium silicate hydrates.

The aim of the present work is to investigate the influence of firing temperature on the properties and surface characteristics of Homra pozzolanic cement pastes.

\section{Experimental}

The materials used in this work were ordinary Portland cement (OPC) provided from Suez Cement Company Egypt and ground clay bricks (Homra) from Misr Brick, Egypt. The chemical composition of starting materials is shown in Table 1. The mineralogical composition of the fired clay bricks is seen from the XRD pattern in Fig. 1. It constitutes mainly of free silica quartz and amorphous aluminosilicate from the decomposition of clay minerals as well as larnite and harturite. It contains high content of free silica from added sand and clay.

TABLE 1. Chemical analysis of the starting materials, (wt, \%) as well as specific surface area $\mathrm{cm}^{2} / \mathrm{g}$.

\begin{tabular}{|c|c|c|c|c|c|c|c|c|c|c|c|}
\hline Oxide & $\mathbf{S i O}_{2}$ & $\mathbf{A l}_{2} \mathbf{O}_{3}$ & $\mathbf{F e}_{2} \mathbf{O}_{3}$ & $\mathbf{C a O}$ & $\mathbf{M g O}$ & $\mathbf{S O}_{3}$ & $\mathbf{K}_{2} \mathbf{O}$ & $\mathbf{N a}_{2} \mathbf{O}$ & $\mathbf{T i O}_{2}$ & I.L & $\begin{array}{c}\text { Surface } \\
\text { area }\left(\mathbf{c m}^{2} / \mathbf{g}\right.\end{array}$ \\
\hline Homra & 69.68 & 11.69 & 10.18 & 2.14 & 1.71 & 2.12 & 0.28 & 0.68 & 1.07 & 0.11 & 3750 \\
\hline OPC & 20.35 & 3.75 & 3.63 & 60.82 & 1.64 & 3.68 & 0.16 & 0.42 & $\cdots$ & 4.31 & 3488 \\
\hline
\end{tabular}

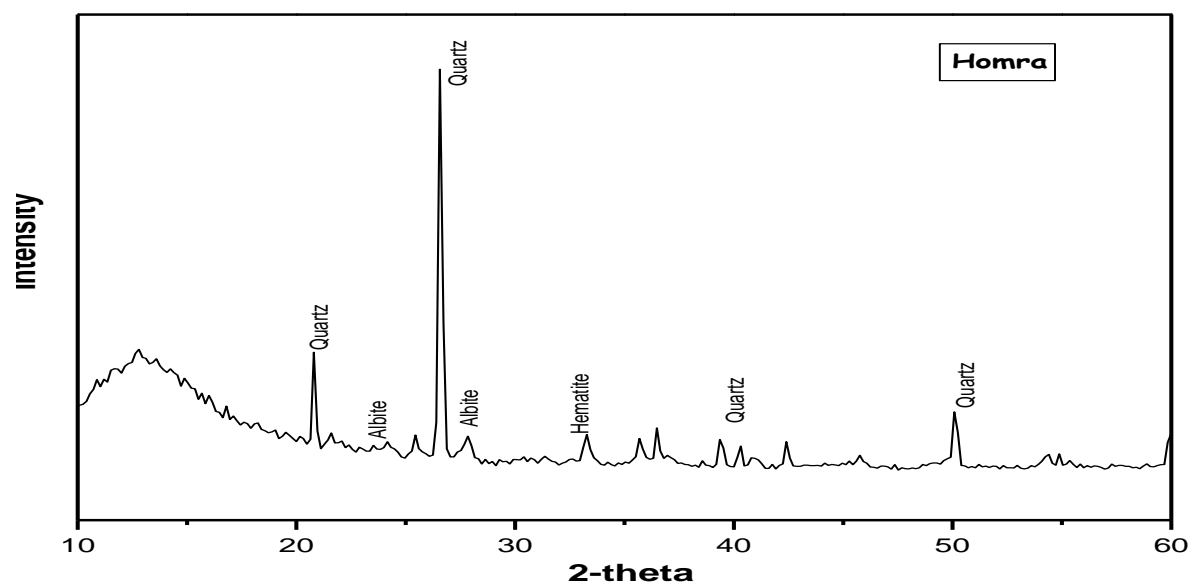

Fig. 1. XRD pattern of clay bricks (Homra).

Egypt. J. Chem. 56, No. 2 (2013) 
Mix composition of the prepared batches is shown in Table 2. Four cements blends were made (Mixes $\mathrm{H}_{1}, \mathrm{H}_{2}, \mathrm{H}_{3}$, and $\mathrm{H}_{4}$ ) with different amounts of Homra and OPC. Each cement blend was mechanically mixed in the dry state for $6 \mathrm{hr}$ in a porcelain ball mill to attain complete homogeneity of the dry mixture and kept in airtight containers until the time of paste preparation.

TABLE 2. The mix composition of the investigated cements, wt \%.

\begin{tabular}{|c|c|c|}
\hline Sample No. & OPC & Homra\% \\
\hline \hline $\mathrm{H}_{0}$ & 100 & 0 \\
\hline $\mathrm{H}_{1}$ & 95 & 5 \\
\hline $\mathrm{H}_{2}$ & 90 & 10 \\
\hline $\mathrm{H}_{3}$ & 85 & 15 \\
\hline $\mathrm{H}_{4}$ & 80 & 20 \\
\hline
\end{tabular}

The fresh cement pastes were prepared from the pozzolanic cement blends in addition to the neat OPC using the standard water of consistency of cement paste $^{(8)}$ The samples were demoulded after $24 \mathrm{hr}$, cured for 28 days under tap water, dried for $24 \mathrm{hr}$ at $105{ }^{\circ} \mathrm{C}$, then subjected to thermal treatment for $2 \mathrm{hr}$ at $250,450,600$ and $800{ }^{\circ} \mathrm{C}$ with a rate of heating of $2{ }^{\circ} \mathrm{C} / \mathrm{min}$, then cooled to room temperature in the furnace. The bulk density, total porosity compressive strength of treated cement pastes were determined after immersing the pastes overnight under kerosene ${ }^{(2,9,10)}$. The free lime content of heat treated cement pastes was determined with ethylene glycol $^{(10)}$.

The XRD technique was carried out using BRUXER, Axs D8 ADVANCE A8, and GERMANY Diffractometer. The microstructure characterization of the sample was done using scanning electron microscope (JEOL 840 SEM with Kevex EDS detector). Surface properties were studied using the nitrogen adsorption technique. From the adsorption isotherms of nitrogen gas at liquid nitrogen temperature, the specific surface areas $\left(\mathrm{S}_{\mathrm{BET}}, \mathrm{m}^{2} / \mathrm{g}\right)$ and total pore volume $\left(\mathrm{V}_{\mathrm{P}} \mathrm{ml} / \mathrm{g}\right)$ could be calculated.

\section{Results and Discussion}

\section{Hydration kinetics}

The bulk density of thermally treated OPC and pozzolanic cement pastes is graphically represented up to $800^{\circ} \mathrm{C}$ in Fig. 2. The bulk density of all cement pastes decreases from $105^{\circ} \mathrm{C}$ up to $250^{\circ} \mathrm{C}$, due to the removal of free or adsorbed as well as combined water from $\mathrm{CSH}$ and $\mathrm{CAH}$ (calcium aluminate hydrate) as well as CASH(calcium aluminoo silicate hydrate), which leads to the formation of micro cracks and opening the pore system of cement pastes. OPC cement paste has higher bulk density than the other pozzolanic cement pastes due to the relatively low density of Homra compared with $\mathrm{OPC}$. From $250^{\circ} \mathrm{C}$ up to $800^{\circ} \mathrm{C}$, the bulk density increases for all cement pastes, due to the decomposition of 
$\mathrm{Ca}(\mathrm{OH})_{2}$ to $\mathrm{CaO}$. Aluminosilicate material reacts with the decomposed $\mathrm{CaO}$ forming denser products. Cement pastes containing $10 \mathrm{wt} \% \mathrm{Homra}\left(\mathrm{H}_{2}\right)$ gives the higher bulk density of all cement pastes than with 5,15 , and $20 \mathrm{wt} \%$. This may be due to that $10 \mathrm{wt} \%$ Homra has the suitable content of quartz which acts as a filler or nucleating agent that accelerates the rate of hydration of pozzolanic cement.

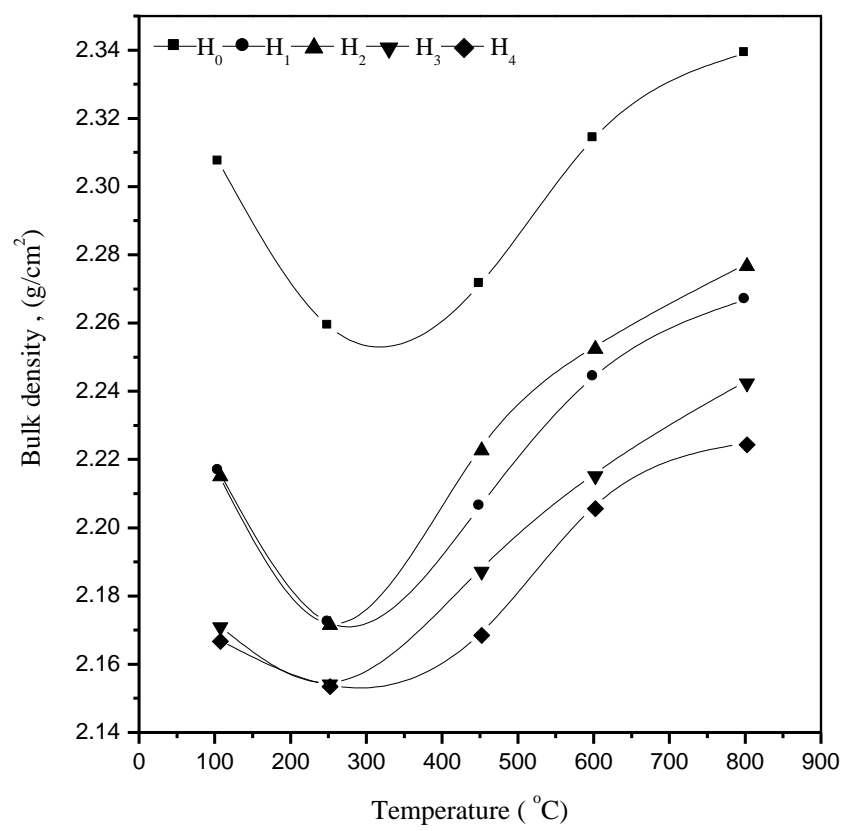

Fig. 2. Bulk density of $\mathrm{H}_{0}, \mathrm{H}_{1}, \mathrm{H}_{2}, \mathrm{H}_{3}$, and $\mathrm{H}_{4}$ cement pastes versus treatment temperature up to $800^{\circ} \mathrm{C}$.

The porosity of OPC and pozzolanic cement pastes is plotted with temperatures in Fig. 3. The porosity of cement pastes increases with Homra content due to the high water of consistency of Homra cement pastes. The porosity decreases with treatment temperature in the range $105^{\circ} \mathrm{C}-250^{\circ} \mathrm{C}$ for OPC $\left(\mathrm{H}_{0}\right)$ cement pastes. This mainly due to that the treatment temperature causes internal autoclaving reaction ${ }^{(11,12)}$ between the liberated lime from cement hydration and Homra. This leads to form more hydration products, which fill some pores then the porosity decreases. On the other side, the porosity of cement paste increases with firing temperature in the range $250-800^{\circ} \mathrm{C}$ due to the formation of micro cracks from the dehydration of $\mathrm{CH}$ (calcium hydroxide) crystals, increase of vapor pressure of steam and crystal transformation of pozzolana minerals as well as the degree of crystallinity of the formed hydrates leading to a sort of opening of the pore system of cement pastes ${ }^{(13,14)}$. The porosity of OPC pastes cannot be determined at $800^{\circ} \mathrm{C}$ due to its deterioration. The cement paste $\mathrm{H}_{2}$ with 10 wt \% Homra shows the lower value of porosity which agrees with that of bulk density.

Egypt. J. Chem. 56, No. 2 (2013) 


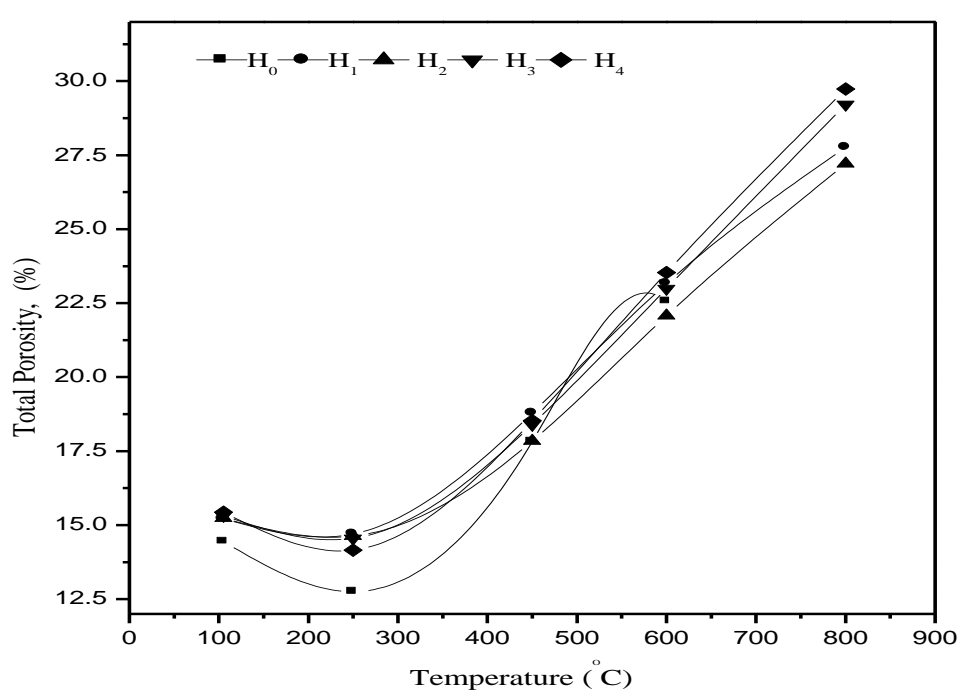

Fig. 3. Porosity of $\mathrm{H}_{0}, \mathrm{H}_{1}, \mathrm{H}_{2}, \mathrm{H}_{3}$ and $\mathrm{H}_{4}$ cement pastes versus treatment temperature up to $800^{\circ} \mathrm{C}$.

Figure 4 shows the variations in compressive strength of thermally treated OPC and pozzolanic cement pastes with temperature. It is clear that the compressive strength of heated cement pastes increases up to $250{ }^{\circ} \mathrm{C}$ as a result of enhancing the hydration of unhydrated cement clinker ${ }^{(15)}$ and the pozzolanic reaction to form extra $\mathrm{CSH}$ with low $\mathrm{Ca} / \mathrm{Si}$ ratio ${ }^{(16)}$. The compressive strength decreases with Homra content from 10-20 wt \% due to the dilution effect of $\mathrm{OPC}$, and increase the water/cement ratio. pozzolanic cement pastes with $5 \mathrm{wt} \%$ Homra $\left(\mathrm{H}_{1}\right)$ gives higher strength at $250^{\circ} \mathrm{C}$ than $\mathrm{OPC}$ due to a nucleating effect which increases the hydration products that increase the compressive strength. The compressive strength decreases at $450^{\circ} \mathrm{C}$, due to the decomposition of cementatious materials, and decomposition of $\mathrm{Ca}(\mathrm{OH})_{2}$, which increase the porosity. The relatively sharp reduction in the compressive at $600^{\circ} \mathrm{C}$ is caused by the transformation of low $\alpha$-quartz to high $\beta$ - quartz at $573^{\circ} \mathrm{C}$ accompanied by a sudden expansion and giving surface and bulk cracks ${ }^{(17)}$. The compressive strength of 20 wt\% Homra cement $\mathrm{H}_{4}$ is higher than all pozzolanic cement pastes. This amount of Homra can react with more $\mathrm{CH}$ (calcium hydroxide) forming dense materials which increase the compressive strength compared with 5 wt $\%$ Homra.

The analysis of XRD patterns of the hardened OPC pastes fired up to $800^{\circ} \mathrm{C}$ are shown in Fig. 5. The results indicate that the intensity of $\mathrm{CSH}$ peak decreases whereas that of larnite $\left(\beta-C_{2} S\right)$ and harturite $\left(C_{3} S\right)$ increase with temperatures. This indicates that CSH gel transforms at high temperature to thermally stable forms of larrnite and harturite minerals. The intensity of $\mathrm{CH}$ peak decreases as result of decomposition as well as partial conversion to calcium carbonate (CC). 
This is evidenced from increasing the intensity of $\mathrm{CC}$ peak at $450^{\circ} \mathrm{C}$. The intensity of $\mathrm{CC}$ peak decreases at $800^{\circ} \mathrm{C}$ as result of its partial decomposition. As the temperature increases up to 800, $\mathrm{CSH}$ gel completely disappeared due to its transformation to larnite and harturite ${ }^{(18,19)}$. This hypothesis is sustained by the parallel increase in the intensity peaks of larnite and harturite at 450 and $800^{\circ} \mathrm{C}$. The presence of portlandite at $800^{\circ} \mathrm{C}$ is mainly due to the rehydration of residual lime $(\mathrm{CaO})$ produced from the decomposition of portlandite as well as $\mathrm{CaCO}_{3}$.

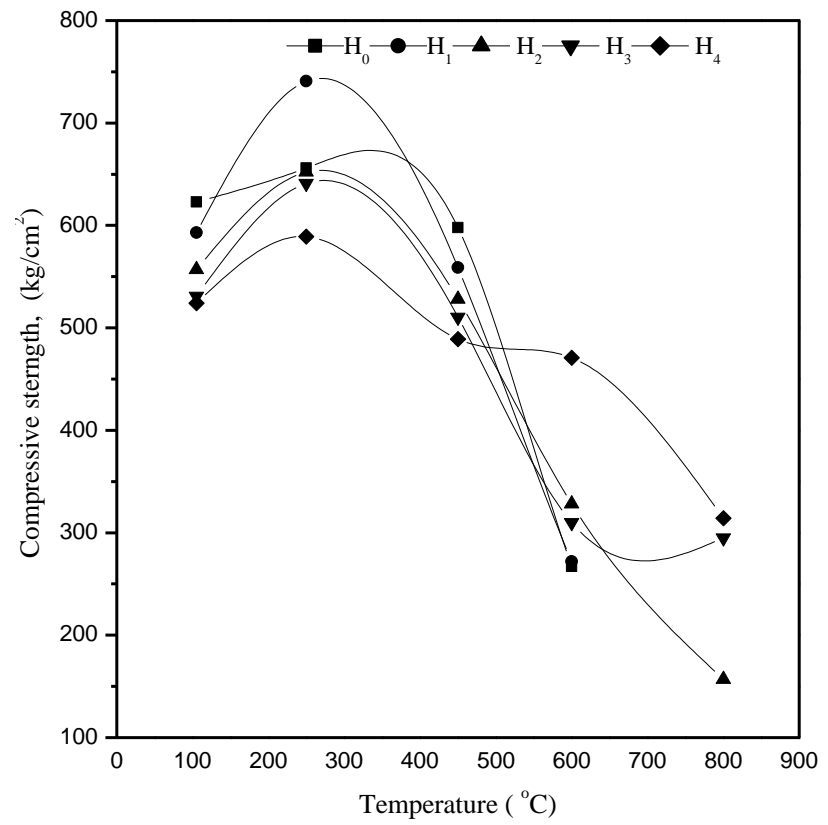

Fig. 4. Compressive strength of $\mathrm{H}_{0}, \mathrm{H}_{1}, \mathrm{H}_{2}, \mathrm{H}_{3}$, and $\mathrm{H}_{4}$ cement pastes as a function of treatment temperature up to $800^{\circ} \mathrm{C}$.

The XRD patterns of the hardened OPC pastes as well as pozzolanic cement pastes with 10 and $20 \mathrm{wt} \%$ Homra fired at $450{ }^{\circ} \mathrm{C}$ are shown in Fig. 6. The results indicate that the peak area of $\mathrm{CH}$ decreases with Homra content due to the high pozzolanic activity which reacts with liberated lime. The intensity of quartz increases with Homra content which is an inert material to react with $\mathrm{CaO}$ at this temperature. The intensity of larnite $\left(\beta-C_{2} S\right)$ and harturite $\left(\mathrm{C}_{3} \mathrm{~S}\right)$ increases due to the reaction of Homra with lime forming additional calcium silicates.

The XRD patterns of hardened pozzolanic cement pastes containing 20 wt $\%$ Homra cement pastes $\left(\mathrm{H}_{4}\right)$ fired up to $800^{\circ} \mathrm{C}$ are shown in Fig.7. The intensity of the diffraction peak of $\mathrm{CH}$ phase decreases with temperature from 450 up to $800^{\circ} \mathrm{C}$. This is mainly due to that the Homra reacts with liberated lime. The intensity of larnite $\left(\beta-C_{2} S\right)$ and harturite $\left(C_{3} S\right)$ increases due to the reaction of Homra with lime.

Egypt. J. Chem. 56, No. 2 (2013) 
The XRD patterns of the heat treated cement pastes at various temperatures illustrate the presence of residual lime. This indicates that heat treatment temperature as well as $5 \mathrm{wt} \%$ pozzolana is insufficient to consume all portlandite. Therefore, the free lime contents of the fired cement pastes are determined to show the residual or unreacted lime with pozzolana.

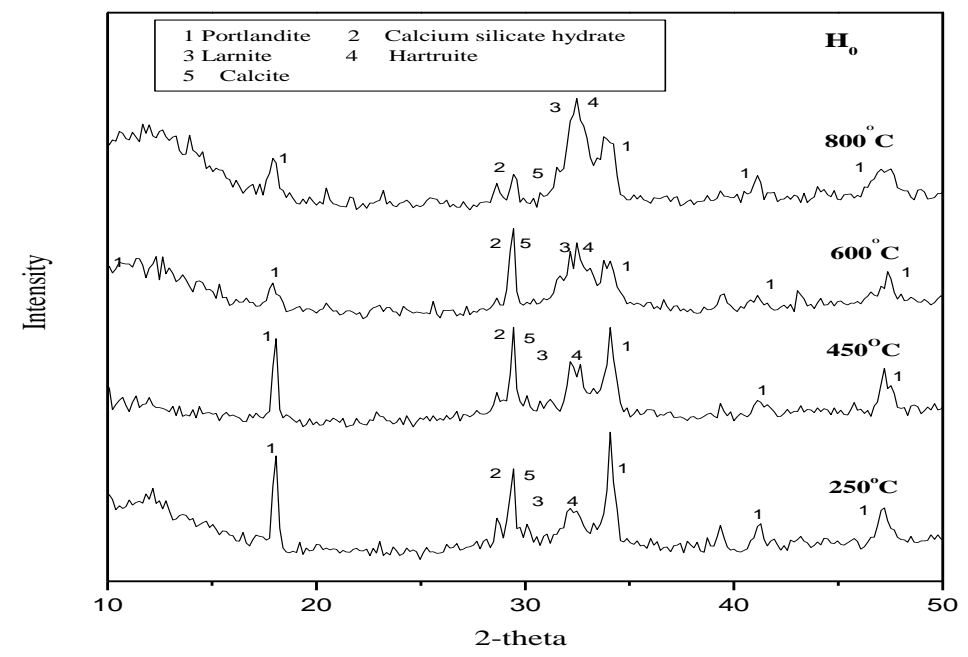

Fig. 5. XRD patterns of hardened OPC $\left(\mathrm{H}_{0}\right)$ pastes fired at $250,450,600,800^{\circ} \mathrm{C}$.

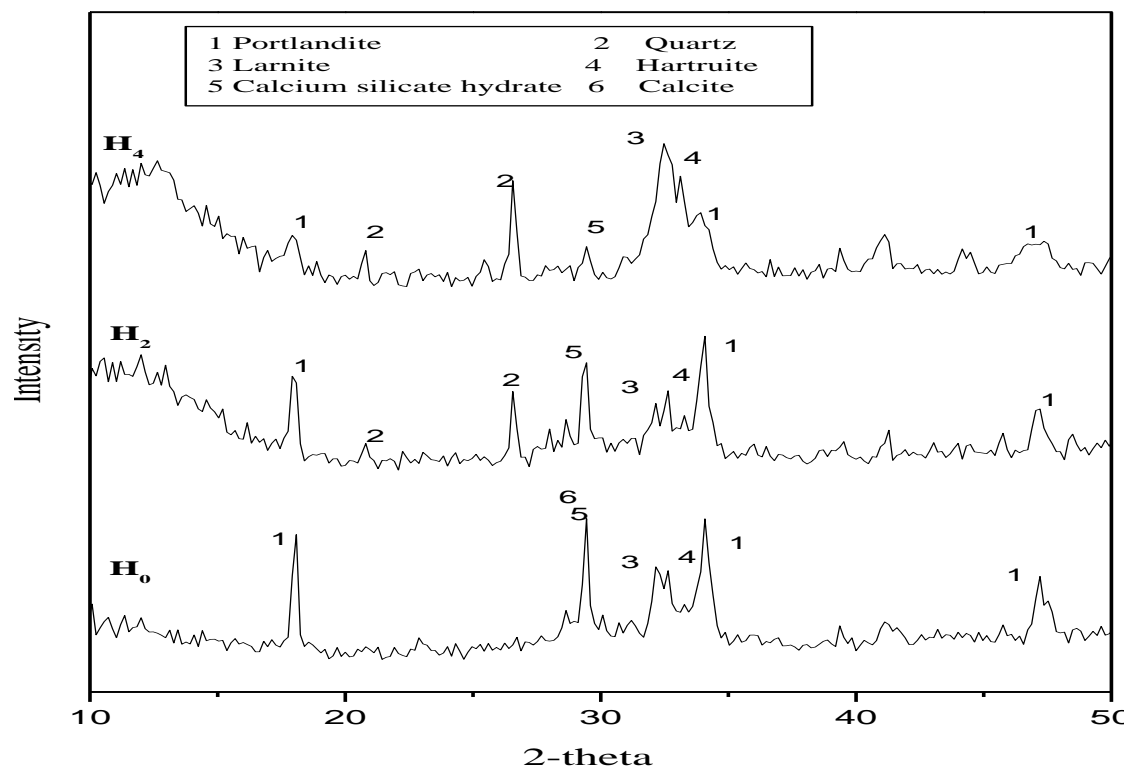

Fig. 6. XRD patterns of hardened $\mathrm{OPC}\left(\mathrm{H}_{0}\right)$ and pozzolanic cement pastes mad with 10 and $20 \mathrm{wt} \%$ Homra and fired at $450^{\circ} \mathrm{C}$.

Egypt. J. Chem. 56, No. 2 (2013) 


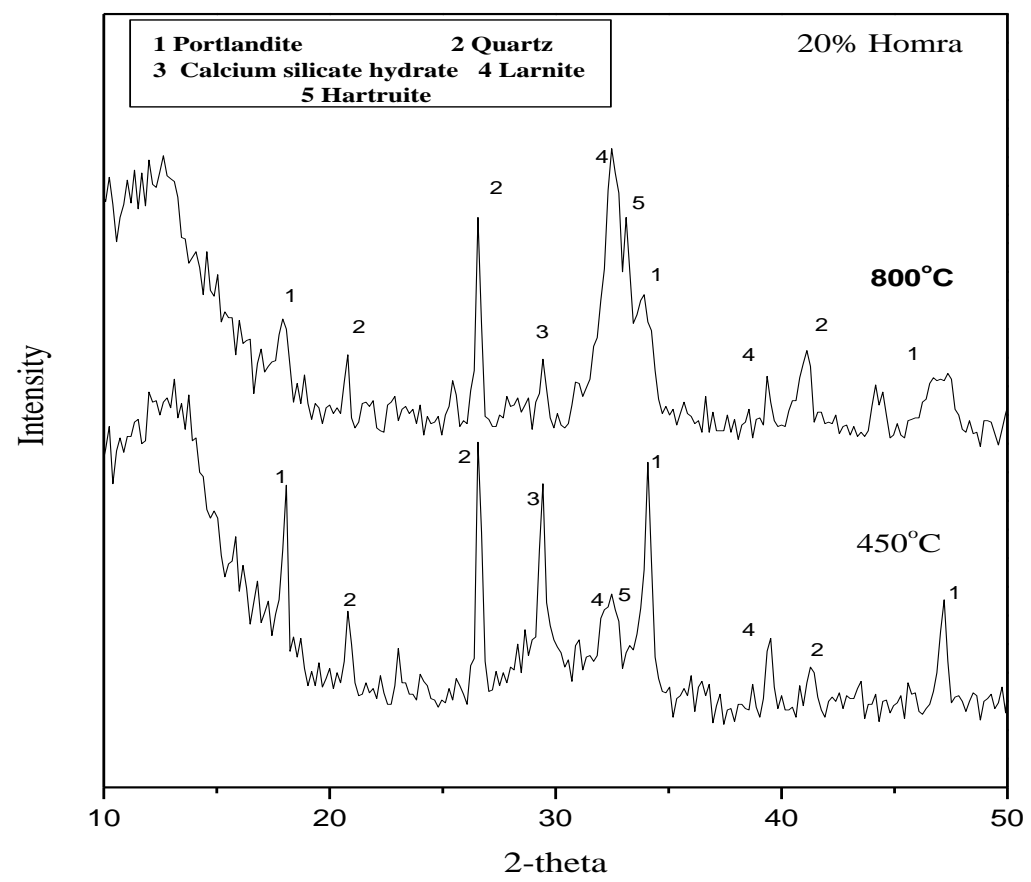

Fig. 7. XRD patterns of Homra pozzolanic cement pastes with $20 \mathrm{wt} \%$ Homra fired at 450 and $800^{\circ} \mathrm{C}$.

The free lime contents of treated OPC and pozzolanic cement pastes up to $800^{\circ} \mathrm{C}$ are plotted in Fig.8. The free lime content decreases with temperature and Homra content. This is mainly due to the reaction between Homra and librated lime to produce hydration products such as $\mathrm{CSH}$ and (CASH). The hydrated cement pastes increases up to $250^{\circ} \mathrm{C}$ due to acceleration of the hydration of unhydrated cement clinker ${ }^{(15)}$ and the pozzolanic reaction to form extra $\mathrm{CSH}^{(16)}$. As the temperature increases up to $600{ }^{\circ} \mathrm{C}$ the free lime decreases due to its dehydroxylation. The presence of portlandite at $800^{\circ} \mathrm{C}$ is mainly due to the rehydration of lime $(\mathrm{CaO})$ from the decomposition of portlandite as well as $\mathrm{CaCO}_{3}$. OPC $\left(\mathrm{H}_{0}\right)$ and $5 \%$ Homra $\left(\mathrm{H}_{1}\right)$ cement pastes give the higher free lime contents than all cement pastes, this is mainly due to that OPC has higher content of carbonated lime which in decomposed giving free lime. On the other side, 5 wt \% Homra can not consume all the librated lime.

\section{Microstructural characterization by SEM}

The SEM micrographs obtained for the pozzolanic cement pastes made of Mix $\mathrm{H}_{4}\left(20\right.$ wt\% Homra) after thermal treatment at $800^{\circ} \mathrm{C}$ are shown in the micrograph in Fig. 9. It illustrates the presence of $\mathrm{Ca}(\mathrm{OH})_{2}$ at $800^{\circ} \mathrm{C}$ as hexagonal crystals and the $\mathrm{CSH}$ as a platy - like morphology arranged in layered structure which produced as result of consumption of hydrated lime by Homra. Some pores and micro crakes are seen. The hydration products were

Egypt. J. Chem. 56, No. 2 (2013) 
deposited in the pore system and around the cement grains. The micro cracks obtained at higher temperature $\left(800^{\circ} \mathrm{C}\right)$ displayed the formation of dense masses of hydration products having micro- and narrow- pores.

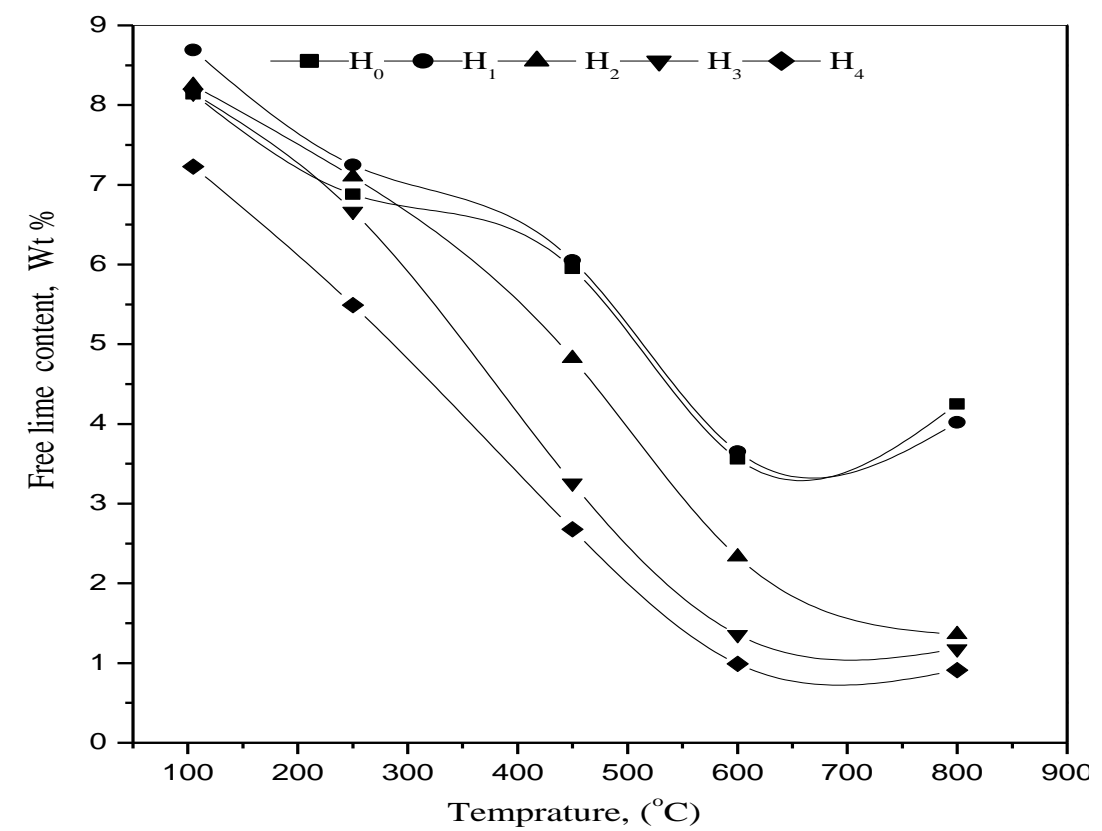

Fig. 8. Free lime content of OPC and Homra pozzolanic cement pastes up to $800^{\circ} \mathrm{C}$.

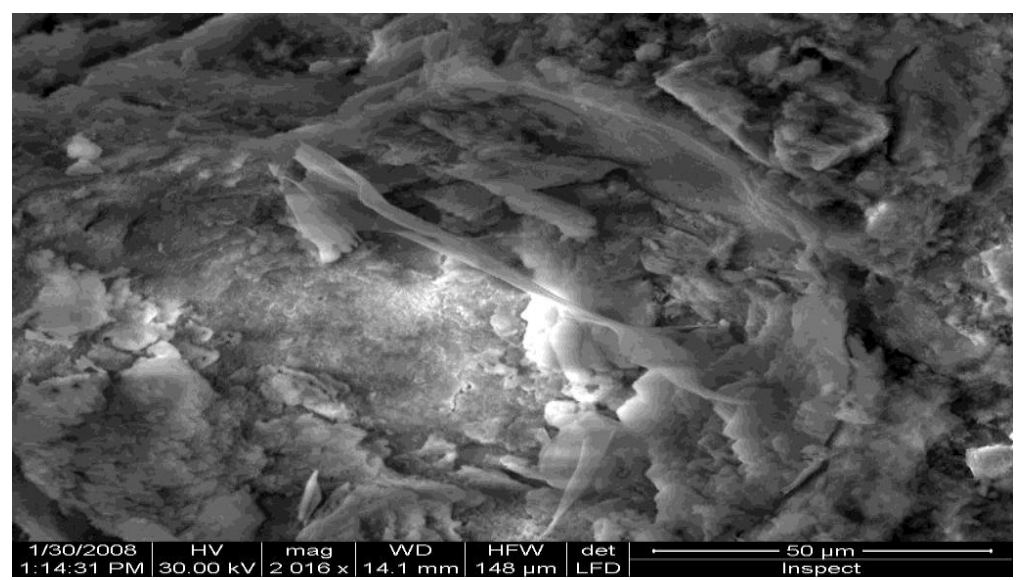

\section{$800^{\circ} \mathrm{C}$}

Fig.9 .The SEM of pozzolanic cement pastes made from OPC with $20 \mathrm{wt} \%$ Homra of heated treated at $800{ }^{\circ} \mathrm{C}$. 
Surface properties

The nitrogen adsorption - desorption isotherms obtained for hardened cement pastes made of Mix $\mathrm{H}_{1}$ after heat treatment at $250{ }^{\circ} \mathrm{C}$ are shown in Fig. 10 . This isotherm shows common characteristics and is similar in shape to type II of Brunauer's classification $^{(20)}$ with narrow and closed hysteresis loops at the high pressure of the isotherms. The specific surface areas, $\mathrm{S}_{\mathrm{BET}}$, could be evaluated by applying the BET equation using the molecular area of nitrogen of $16.2 \mathrm{~A}^{2}(21)$ and the values are shown in Fig. 11. The total pore volume, $V_{p}$, were taken as the saturation values of the isotherms and are expressed in $\mathrm{ml} / \mathrm{g}$; the $\mathrm{V}_{\mathrm{p}}$ - values are shown in Fig. 12.

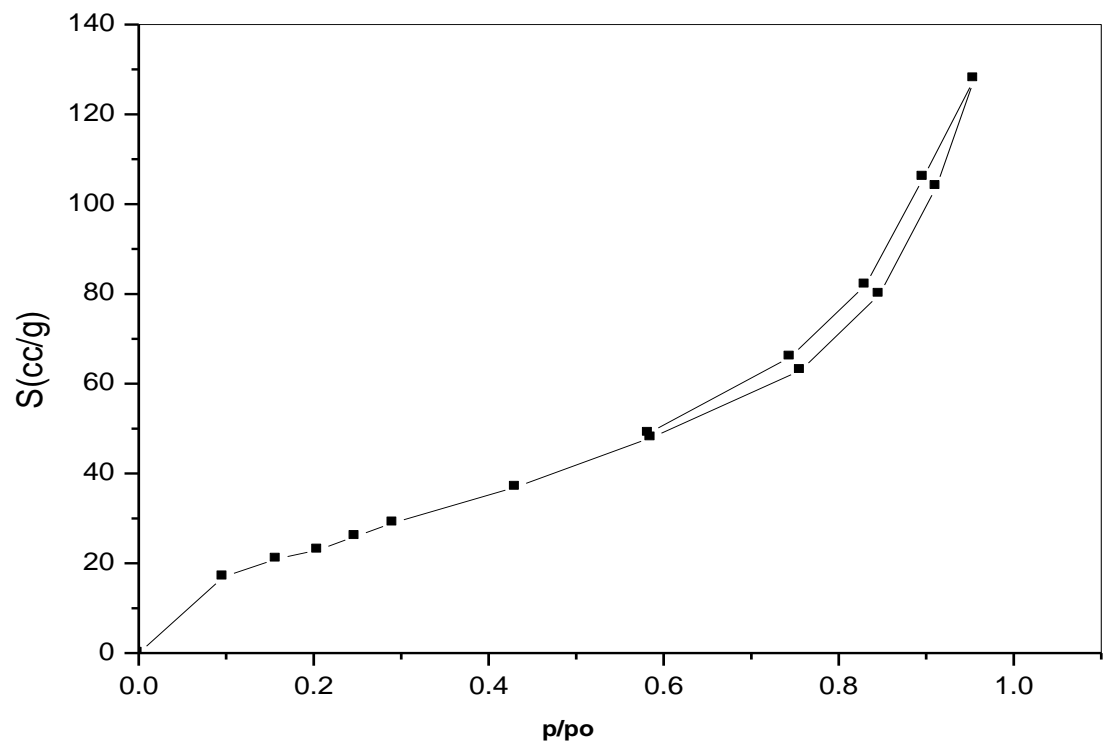

Fig.10. Adsorption- desorption isotherms of nitrogen on the hardened cement pastes made of Mix I after heat treatment $250^{\circ} \mathrm{C}$.

Evidently, the results of Fig. 11 and 12 indicated that the specific surface area as well as the total pore volume increase with increasing Homra content in the pozzolanic cement pastes from $5 \%$ in $\mathrm{Mix}_{1}$ to $20 \%$ in $\mathrm{Mix}_{4}$. This result is mainly attributed to the decrease in the degree of crystallinity of the formed hydration products with increasing Homra content; microcrystalline hydrates possess higher surface area as compared with high crystalline hydrates. In addition, there appeared an initial decrease in the surface area and total pore volume with increasing temperature of thermal treatment from 105 to $250^{\circ} \mathrm{C}$, this result is mainly attributed to the internal autoclaving effect ${ }^{(22)}$ which leads to the formation of additional amounts of hydration products as a result of the hydrothermal reaction. With increasing temperature above $250^{\circ} \mathrm{C}$ a continuous increase in both of the surface area $\left(\mathrm{S}_{\mathrm{BET}}\right)$ and total pore volume $(\mathrm{Vp})$ was observed from 250 to $800^{\circ} \mathrm{C}$; this result is mainly due to the well crystallization and /or the formation of micro cracks with increasing temperature of heat

Egypt. J. Chem. 56, No. 2 (2013) 
treatment. These two effects lead to a sort of pore-opening leading to an increase in the accessibility of nitrogen molecules to measure larger fractions of the total pore system.

Obviously, similar variations in the values of the surface area and total pore volume were observed with increasing temperature of thermal treatment. This indicates that nitrogen molecules can measure the same kind of pores, namely, mesopores. Since nitrogen molecules are inaccessible from parts of the pore system of the hardened cement pastes by two mechanism : either the pores are too narrow or the pore entrances are too narrow to admit nitrogen molecules ${ }^{(23,24)}$.

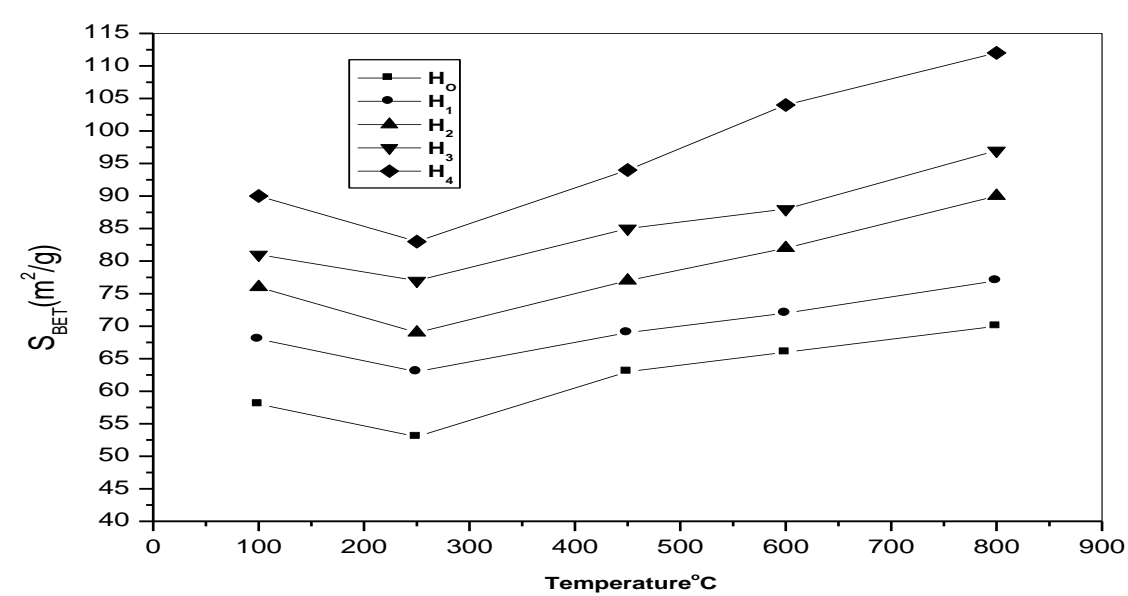

Fig.11. Variations of the specific surface areas of the hardened pozzolanic cement pastes with temperature of heat treatment .

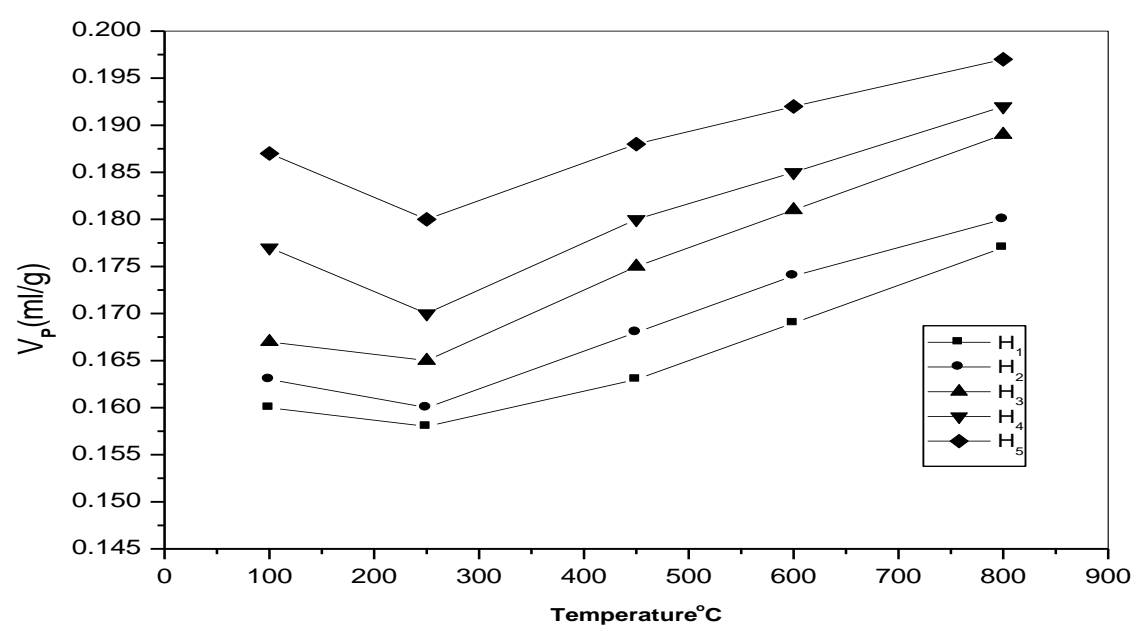

Fig. 12. Variations of pore volumes of the hardened pozzolanic cement pastes with temperature of thermal treatment . 


\section{Conclusions}

The main conclusions derived from this study can be summarized as follows: - OPC pastes have low resistance to heat treatment up to $600^{\circ} \mathrm{C}$ due to the presence of high content of portlandite.

- Homra improves the fire resistance of hardened blended cement pastes and the width of formed surface cracks decreases with increasing Homra content. This is mainly due to the pozzolanic activity of Homra, which interacts with the free lime liberated from OPC hydration leading to the formation of amounts of CSH gel and CASH which transform at higher temperature to the thermally stable larnite and harturite minerals.

- Firing at $800^{\circ} \mathrm{C}$ of pozzolanic cement paste made with 20 wt \% burnt clay (Homra) resulted in an increase in compressive strength and porosity with decrease in free lime content and bulk density as compared to OPC.

- OPC substituted with 5 wt \% Homra can't be considered as fire resisting cement ; while pozzolanic cement blend contains 20 wt \% Homra represents cement with high fire resistance and low density.

- The specific surface area as well as total pore volume increase with increasing Homra content in the pozzolanic cement pastes from 5\% in $\mathrm{Mix}_{1}$ to $20 \%$ in Mix $\mathrm{H}_{4}$.

\section{References}

1. Galle, C. and Sercombe, J., Permeability and pore structure evolution of silicocalcareous and hematite high strength concrete submitted to high temperature. Material Structure, 33, 619- 628 (2001).

2. El-Didamony, H., Abd El-Rahman, E. and Osman, R.M., Fire resistance offired clay bricks-fly ash composite cement pastes, Ceramic. International 38, 201-209 (2012).

3. Heikal, M., El Didamony, H. and Ali, A.H., Pozzolanic action of Homra with lime. Indian J. Eng. Mater. Sci. 7, 45- 159 (2000).

4. Heikal, M. and El-Didamony, H., Pozzolanic activity of Homra with lime. Man. Sci. Bull. A. Chem. 26 (1), 79-95(1999).

5. Gupta, J.S., Technology option for manufacture of calcined clay pozzolan (surkhi). In: Hill N., Holmes S. Mather, D, (Ed.) Lime and Other Alternative Cements. London: Intermediate Technology Publications Ltd., pp. 191-8 (1992).

6. O'Farrell, M., Sabir, B.B. and Wild, S., Strength and chemical resistance of mortars containing brick manufacturing clays subjected to different treatments. Cem. Concr. Compos. 28, 790-799 (2006).

7. Heikal, M., Effect of temperature on the physico- mechanical and mineralogical properties of Homra pozzolanic cement pastes. Cem. Concr. Res. 30, 1835-1839 (2000).

Egypt. J. Chem. 56, No. 2 (2013) 
8. ASTM Designation, C191, Standard Test Method for Normal Consistency and Setting Time of Hydraulic Cement, Annual Book of ASTM Standard 04.01. (2008).

9. ASTM Designation, C 150, Standard Test Methods for Compressive Strength of Hydraulic Cements, ASTM Standard, pp. 710-736 (2007).

10. ASTM Designation, C114-88, Standard Test Methods for Chemical Analysis of Hydraulic Cement, ASTM Standards, pp. 710-736 (1990).

11. Abd-El-Wahed, M.G., El-Didamony, H., Amin, A.M. and Taha, A.S., Hydration of granulated slag-alite in the presence of quartz. J. Mater. Sci. 24, 276 -283 (1989).

12. Piasta, J., Sawiz, Z. and Rudzinki, L., Changes in structure of hardened cement pastes due to high temperature. ACI Material Construction, 171, 291-296 (1984).

13. Saad, M., Abo-El-Enein, S.A., Hanna, G.B. and Kotkata, M.F., Effect of silica fume on the phase composition and microstructure of thermal treated concrete. Cem. Concr. Compos. 26, 1479-1484 (1996).

14. Tantawy, M.A., The Physico- chemical properties of pozzolanic-filled cement pastes, Ph.D. Thesis, Fac. Sci. El- Minia University, Egypt (2008).

15. Walters, G.V. and Jones, T.R., Effect of metakaolin on alkali-silica reaction (asr) in concrete manufactured with reactive aggregate. Durability of concrete, Second International Conference, 2, 941-23-27 (1991).

16. Chan, S.Y.N. and Anson, G.F., Residual strength and pore structure of high strength concrete and normal strength concrete after exposure to high temperatures. Cem. Concr. Compos. 21, 23-27 (1999).

17. Taylor, H.F.W., Cement Chemistry, Academic Press Inc, London, II (1990).

18. Alonso, C. and Fernandez, L., Dehydration and rehydration processes of cement pastes exposed to high temperature environments. J. Mater. Sci. 29, 3015 (2004).

19. Heikal, M., Effect of temperature on the structure and strength properties of cement pastes containing fly ash alone or in combination with limestone. Cermics- Silicaty. 50, 167 (2006).

20. Brunaur, S., Emmett, P.H. and Teller, E., Adsorption of gases in multimoleculr layers. J. Amer. Chem. Soc. 60, 309-319 (1938).

21. Lippens, B.L., Linsen, B.G. and De Boer, J.H., Studies on pore system in catalyst1.The adsorption of nitrogen, apparatus and calculation. J. Catalysis, 3, 32 (1964).

22. Saad, M., Abo-El-Enein, S.A., Hanna, G.B. and Kotkata, M.F., Effect of phas composition and microstructure of thermally treated concrete, Cem. Concr Res. 26 (5), 669-676 (1996). 
23. Mikhalil, R.Sh., Abo-Elnein, S.A. and Abd-El-Khalik, M., Hardened slag cement pastes of various porosities. II- water and nitrogen adsorption. J. Apple. Chem. Biotechnol. 25, 835-847(1975).

24. Abo- El- Enein, S.A., Daimon, M., Ohsawa, S. and Kando, R., Hydration of low porosity slag-lime pastes. Cem. Concr. Res. 4, 299-312 (1974).

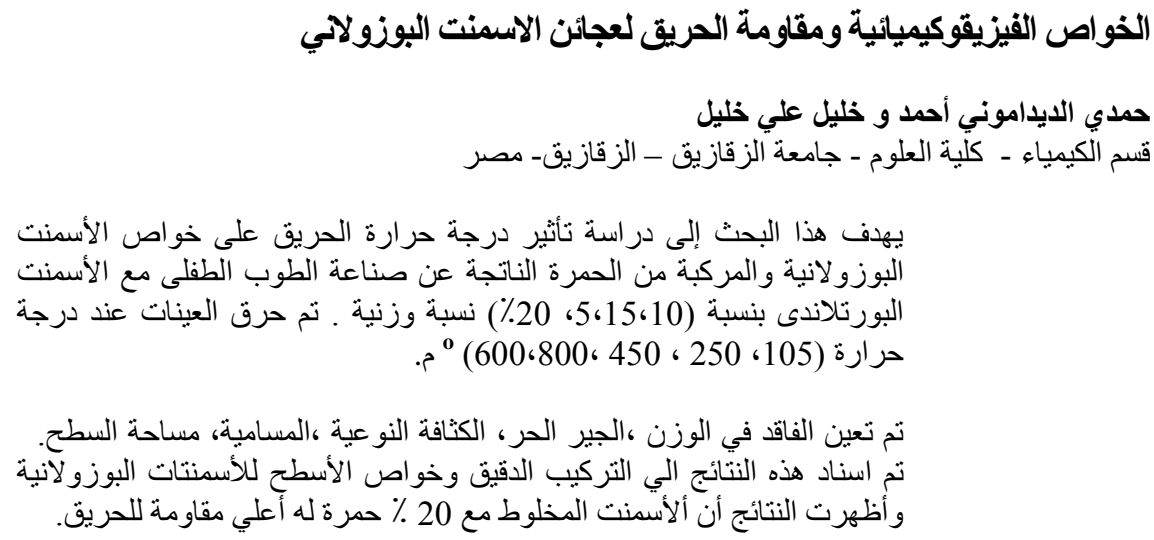

Egypt. J. Chem. 56, No. 2 (2013) 